\title{
Finite Element Analysis of PEB using Ready Reckoner for Moment Connection
}

\author{
${ }^{\text {"1 }}$ Sharda P. Siddh, ${ }^{2}$ Shubham Mishra, ${ }^{3}$ Hariom P. Khungar, ${ }^{4}$ Tripti B. Gupta, \\ ${ }^{1,3,4}$ Civil Engineering Department, Shri Ramdeobaba College of Engineering and Management, Nagpur-13 \\ ${ }^{2}$ Zamil Steel Buildings India Pvt. Ltd., Pune, India. \\ Email: shardasiddh.9@gmail.com,shubham15494@gmail.com,khungarhp@rknec.edu,guptatb@rknec.edu
}

Received: 06th November 2019, Accepted: 10th February 2020, Published: 29th February 2020

\begin{abstract}
These days because of mushroom development of PEB, quality of structural connection is ignored and in such cases this reckoner will help in giving the proficient and upgraded design. Ready Reckoner implies ready reference table which plans moment connection effectively as it gives the required values. With different size of moment connections, design capacity of bolts in shear, tension is acquired. All the while connection end plate thickness is additionally found out and the outcomes were validated with the help of finite element analysis software ANSYS. Results were obtained with the help of manual calculation. Different number of section sizes considered, different diameter of bolt is considered and different bolt combination is considered. It will help the practicing structural engineers to calculate the connection capacity of different sections sizes.
\end{abstract}

Keywords

Pre-Engineered Building, Ready-Reckoner, Moment Connections, Finite Element Analysis.

\section{Introduction}

Improvement in the technology over the decades has immensely contributed to enhance the standard of living and quality of life with different new services and products. Pre Engineered Buildings (PEB) was one of such upheaval. PEB is the structures which are designed at an industrial facility and collected at site. Normally PEBs are steel structures. Figure 1 shows the pre-built steel building parts, which gives the possibility of the segment is there in a PEB industry. It gives surrounding framework and supporting framework.

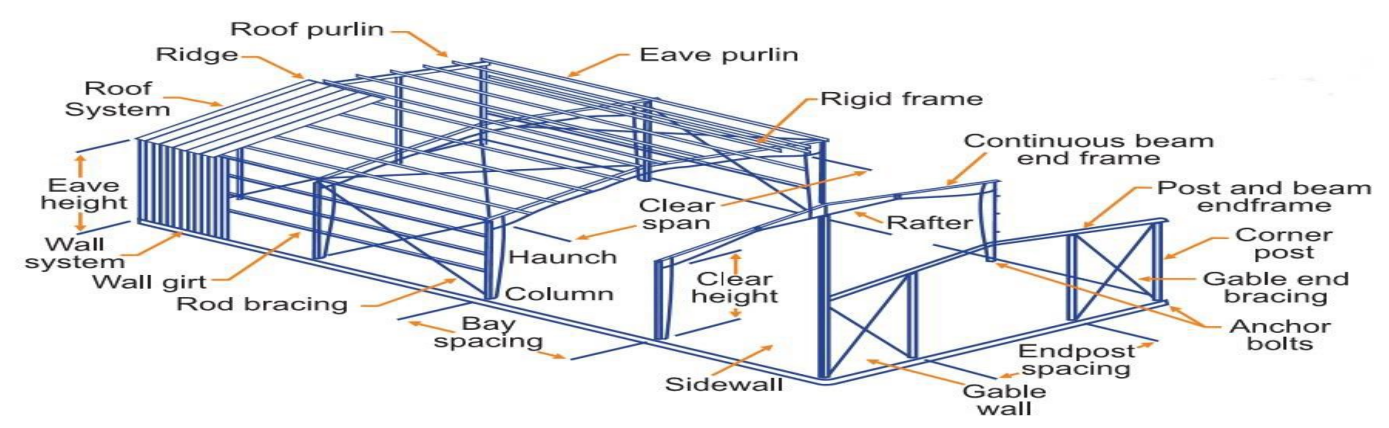

Fig. 1: Typical Pre-engineered Steel Buildings

Researchers have proposed certain plan conditions to give more advanced more slender end plate associations then the past got condition [10]. Several authors have considered strength of double-row bolted-web connections [9] and conducted research on recent developments for the design of moment end-plate connections [25]. Design methods for both flush and extended end-plate configurations, including column side limit states. Manual calculation to evaluate the three column side limit states (web buckling, web yielding and flange bending) and with the help of finite element studies. This study checks the recent development done on design of moment End-plate connections and compares the results with finite element study. Research was conducted on connection performance for seismic design of steel moment [8]. It gives a review of the issues required to guarantee great seismic execution of steel moment frame connections. This paper manage the experimentation explore, which gives proper connections. Number of connections was assessed, and three techniques were utilized to improve the seismic exhibition of various connections. The three connections are the welded-spine welded-web, decreased bar segment, and catapulted rib plate connections. Later on study was done on various section sizes of moment connection, design capacity of bolts in shear, tension and connected extended end plate thickness were obtained [1][22][24].

Study was carried out on double-shear trial of high-strength bolts at raised temperatures [23]. It was test study where the behaviour of bolts was studied especially under shear loading at raised temperatures. Test was led on high-strength bolts subjected under double shear loading that to be at expanded temperature. During the 
experiment, various parameters, for example, temperature, bolt measurement and grade of bolt were changed. Bolt grade utilized in the test was A325 and A490. At five distinct temperatures, three unique breadths for each evaluation of bolt 23 were tried. Aftereffects of the directed test explained that at high temperature, shear behaviour of high strength bolt will carry on. As the temperature is expanding there is debasement of material properties, for example, stiffness, strength and mechanical properties of high quality steel bolts.

New bolt-slip model for high strength bolted connection were also studied and simplified numerical model for high-strength bolted connections were proposed [27]. In this paper they study and proposed the. They also proposed the real constant of the frictional element and the method to determine the same. They compared the results derived by the existing numerical model and experimental work with the newly proposed bolt-slip model. A result concluded by the comparison of the results is that the friction force with sufficient accuracy can be derived from the proposed bolt-slip model and it well captured the sliding phenomenon. This bolt-slip model is suitable for large strain analysis and for large deformation. So this newly introduce bolt-slip model significantly reduce computation time with high accuracy.

Authors [27] have also invigorated improved numerical model for high-strength bolted connections. Authors have proposed the new bolt slip model for high-strength bolted connections. They likewise proposed the genuine constant of the frictional component and the method to decide the equivalent. They looked at the outcomes determined by the current numerical model and experimental work with the proposed bolt slip model. A result closed by the examination of the outcomes is that the friction force with adequate accuracy can be derived from the proposed bolt slip model it well captured the sliding phenomenon. This bolt slip model is appropriate for enormous strain examination and for large deformation. This bolt slip model fundamentally reduced the calculation time with high precision.

\section{Methodology}

The various parameters taken in ready reckoner are different flanges width, flange thickness varying with different web depth and web thickness. Along with different section sizes, diameter of bolts is taken and different thickness of end plate is suggested. With this manual calculations 3D finite element model is created in ANSYS to cross check the values which are obtained. Haunch or Knee Connection, Ridge Connection and splice plate Connection are the main areas of study in this paper and it's the analytical study. Limit state method is used for designing of connections which includes Bolts and End pate. With the help of manual calculations Design is based on the simple logic given below, which shows that when force is multiplied with the distance it creates moment. F x D = M; Where, F is the bolt force coming from all the bolts on one side of flange. D is the lever arm distance considering from center to center distance of the flanges.

\section{Modelling of Rafter, Splice Plate, Gusset and Bolts:}

All the plates modeled in ANSYS are of same grade, specification and property which include beam web, flanges and gusset and splice plates (end plate). Modelling of bolts is done in ANSYS with different grade and property.

\section{Section Size Consideration:}

In this study, First ANSYS model of section size consider as the flange width of $130 \mathrm{~mm}$ and flange thickness of $6 \mathrm{~mm}$ and web depth of $400 \mathrm{~mm}$ and web thickness of $4 \mathrm{~mm}$ whereas plate depth, width, thickness are 620 $\mathrm{mm}, 200 \mathrm{~mm}$ and $16 \mathrm{~mm}$ respectively. Plate thickness is calculated as per bolts and section size. Bolts of $16 \mathrm{~mm}$ diameter are the minimum requirement in the moment connection. Moment applied in the ANSYS model is first calculated manually with the basic assumptions that in I-section, flange will take care of the moment and web will take care of shear only.

\section{Engineering and Material Properties:}

Material and engineering properties plays an important role in any type of analysis. Here built up section material property is considered as $345 \mathrm{MPa}$ whereas for the bolts it is considered as 8.8 grade bolt. So yield strength of bolt is taken as $640 \mathrm{MPa}$ and ultimate tensile strength as $800 \mathrm{MPa}$.

Arrangement of Bolts:

Connection capacity can be found out with the help of ready reckoner. Table gives direct results in terms of diameter of bolt, number of bolts and required plate thickness of the connecting plates. Now arrangement of bolts plays important role as well, as it can leads to make changes in the result. Few arrangement of the bolted connection is depicted in the given figure below. Line body diagram for the better clarification of stiffeners front view and side view is given. 


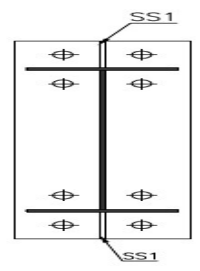

a. Without Stiffener

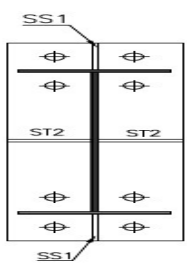

b. With Stiffener

Fig. 2: Typical Arrangement of 8 Bolts in PEB Connection

\section{Results and Discussion}

In this work results are calculated for different diameter, number of bolts and for different section sizes. Results presented in the ready reckoner table are calculated manually. Some random sample collected and modelled in ANSYS workbench. Finite element analysis supports the work carryout under this project.

Bolt Stresses: Whereas in case of bolts, stress values coming out to be only 507.39MPa. Which states that our bolt capacity has not even crossed its yielding zone, with the help of contours i.e. figure 3 . Concluding by the ANSYS results that our section is showing some stresses which crossed it given yielding value whereas, in case of bolts it is very safe.

\begin{tabular}{|c|c|c|c|c|c|c|c|c|c|c|c|c|c|}
\hline & \multicolumn{2}{|l|}{ Web } & \multicolumn{2}{|c|}{ Flange } & \multicolumn{2}{|l|}{ Bolt } & \multicolumn{3}{|c|}{ Bolt Capacity } & \multicolumn{3}{|c|}{ Section Capacity } & \multirow{2}{*}{$\begin{array}{l}\text { Plate } \\
\text { thickness }\end{array}$} \\
\hline & Depth & $\begin{array}{l}\text { Thic } \\
\text { kness }\end{array}$ & $\begin{array}{l}\text { Wid } \\
\text { th }\end{array}$ & $\begin{array}{l}\text { Thick } \\
\text { ness }\end{array}$ & $\begin{array}{l}\text { Diam } \\
\text { eter }\end{array}$ & $\begin{array}{l}\text { Num } \\
\text { bers }\end{array}$ & $\begin{array}{l}\text { She } \\
\text { ar }\end{array}$ & $\begin{array}{l}\text { Tensi } \\
\text { on }\end{array}$ & Moment & Shear & Tension & Moment & \\
\hline unit & $\mathbf{m m}$ & $\mathbf{m m}$ & $\mathbf{m m}$ & $\mathbf{m m}$ & $\mathbf{m m}$ & n & $\mathbf{k N}$ & $\mathbf{k N}$ & kN-m & $\mathbf{k N}$ & $\mathbf{k N}$ & kN-m & $\mathbf{m m}$ \\
\hline \multicolumn{14}{|l|}{ S.N } \\
\hline 1 & 300 & 4 & 130 & 5 & 16 & 8 & 456 & 360 & 110 & 215 & 202 & 62 & 16 \\
\hline 2 & 300 & 4 & 130 & 6 & 16 & 8 & 456 & 360 & 110 & 215 & 242 & 74 & 16 \\
\hline 3 & 300 & 4 & 150 & 5 & 16 & 8 & 456 & 360 & 110 & 215 & 233 & 71 & 16 \\
\hline 4 & 300 & 4 & 150 & 6 & 16 & 8 & 456 & 360 & 110 & 215 & 279 & 86 & 16 \\
\hline 5 & 350 & 4 & 130 & 5 & 16 & 8 & 456 & 360 & 128 & 251 & 202 & 72 & 16 \\
\hline 6 & 350 & 4 & 130 & 6 & 16 & 8 & 456 & 360 & 129 & 251 & 242 & 86 & 16 \\
\hline 7 & 350 & 4 & 150 & 5 & 16 & 8 & 456 & 360 & 128 & 251 & 233 & 83 & 16 \\
\hline 8 & 350 & 4 & 150 & 6 & 16 & 8 & 456 & 360 & 129 & 251 & 279 & 99 & 16 \\
\hline 9 & 400 & 4 & 130 & 5 & 16 & 8 & 456 & 360 & 146 & 287 & 202 & 82 & 16 \\
\hline 10 & 400 & 4 & 130 & 6 & 16 & 8 & 456 & 360 & 146 & 287 & 242 & 98 & 16 \\
\hline 11 & 400 & 4 & 130 & 8 & 16 & 8 & 456 & 360 & 147 & 287 & 323 & 132 & 16 \\
\hline 12 & 400 & 4 & 150 & 5 & 16 & 8 & 456 & 360 & 146 & 287 & 233 & 94 & 16 \\
\hline 13 & 400 & 4 & 150 & 6 & 16 & 8 & 456 & 360 & 146 & 287 & 279 & 113 & 16 \\
\hline 14 & 400 & 4 & 150 & 8 & 20 & 8 & 720 & 564 & 230 & 287 & 373 & 152 & 20 \\
\hline 15 & 450 & 4 & 130 & 5 & 16 & 8 & 456 & 360 & 164 & 323 & 202 & 92 & 16 \\
\hline 16 & 450 & 4 & 130 & 6 & 16 & 8 & 456 & 360 & 164 & 323 & 242 & 110 & 16 \\
\hline 17 & 450 & 4 & 130 & 8 & 16 & 8 & 456 & 360 & 165 & 323 & 202 & 92 & 16 \\
\hline 18 & 450 & 4 & 150 & 5 & 16 & 8 & 456 & 360 & 164 & 323 & 233 & 106 & 16 \\
\hline 19 & 450 & 4 & 150 & 6 & 16 & 8 & 456 & 360 & 164 & 323 & 279 & 127 & 16 \\
\hline 20 & 450 & 4 & 150 & 8 & 20 & 8 & 720 & 564 & 258 & 323 & 373 & 171 & 20 \\
\hline
\end{tabular}

Table 1: Ready Reckoner Table for Load Capacity of Moment Connection in PEB

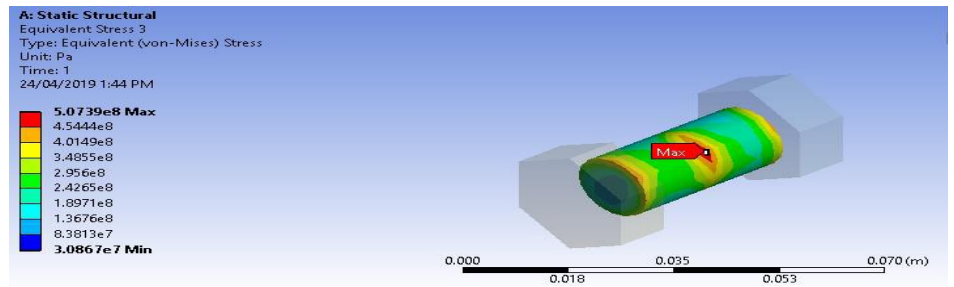

Fig. 3: Equivalent Stress of Section

Plate Stresses:

It shows that basic assumption during plate designing was correct that the beams are cantilevered and restrained against rotation at one end, and fixed at other end (i.e. at bolt line). Figure 4 shows the plate stresses under loading. It also shows tension side of plate, maximum stresses are near the flange, gusset and web of the section as that is the location of contact between plate and section. Where in the case of compression side in figure $b$ of enlarge view of plate stresses under loading, it shows that only stress are concentrated near flange and web interaction as due to bending it is taking compression only. 


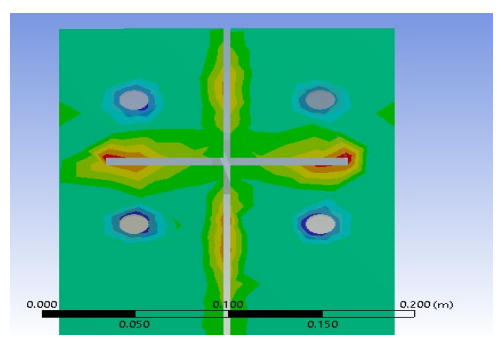

a. Tension Side

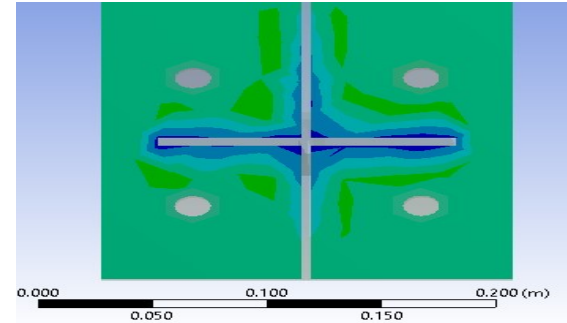

b. Compression Side

Fig. 4: Enlarge View of Plate Stresses under Loading

\section{Conclusions}

With the help of this research it can be concluded that, Ready reckoner can be used to find out the load capacity of moment connection in pre-engineered steel building. Connecting plate thickness of the moment connection can be obtained from ready reckoner table. Bolt load carrying capacity in shear and tension is obtained. Result from ANSYS software supports the manually calculated results in the ready reckoner. This ready reckoner table is applicable up to the web depth of $450 \mathrm{~mm}$ only. This table can be used by the structural engineers; results of this table should not be following blindly. In case of any dispute in the designing part of the bolts, one should consult the practicing structural engineer. In case of future scope, it is possible to make ready reckoner for load capacity for Horizontal knee connection in pre-engineered steel building. As the horizontal knee connection is also used in pre-engineered steel buildings because of its various advantages. It gives clear height as no bolts are provided in the inner side of the flange, which makes it easy for bolting.

\section{References}

1. Ahmed Hassan Youssef et.al, "Behavior of I-beam bolted extended end-plate moment connections", Ain Shams Engineering Journal, Pp 685-699, April 2013, Elsevier B.V.

2. AISC (1989), Specification for Structural Steel Buildings Allowable Stress Design and Plastic Design.(ASD89).

3. AISI (2001), North American Specification for the Design of Cold-formed Structural Steel Members.

4. AISC (2011), Steel Construction Manual, Fourteenth Edition.

5. ANSI-AWS (2008), AWS D1.1/D1.1M, Structural Welding Code - Steel.

6. Alexander Newman, Metal Building Systems:Design \& Specifications Second Edition,2005, McGraw Hill.

7. Arya A.S. and Ajmani J.L., "Design of Steel Structures", Nemchand \& Bros, Roorkee, 1996.

8. Charles W. Roeder, "Connection Performance for Seismic Design of Steel Moment Frames", Journal of Structural Engineering, Vol. 128, No. 4, April 1, 2002 ,ASCE.

9. James M. Ricles \& Joseph A. Yura," Strength of Double-Row Bolted-Web Connections", Journal Structure Engineering, Vol. 109, No. 1, January 1983, ASCE.

10. Krishnamurthy N., "Fresh Look at Bolted End-Plate Behavior and Design," Engineering Journal, Vol. 15, No. 2, 1978, pp. 39-49.

11. INSDAG, Design Guidebook for Portal Type Pre-Engineered Building. Publication INS/PUB/080.

12. INSDAG, "Design of Single Span Steel Portal Frames to BS 5950-1:2000", Publication INS/PUB 090, Feb 2007, P252.

13. INSDAG (2010), Design Manual For Designing Steel Structures According to New IS800:2007.

14. IS SP6 (2):1962. Reaffirmed 2003 Indian Standard Handbook for Structural Engineers. Part 2. Steel Beam \& Plate Girders.

15. IS 800:1984. Indian Standard Code of Practice for General Construction In Steel.

16. IS 800:2007. Indian Standard General Construction in Steel - Code of Practice.

17. IS 801:1975 Indian Standard Code of Practice For Use of Cold-formed Light Gauge Steel Structural Members in General Building Construction.

18. IS 875:1987 Indian Standard Code of Practice for Design Loads (Other than Earthquake) For Buildings and Structures, Part I to V. 60

19. IS 1893:2002 Indian Standard Criteria For Earthquake Resistant Design of Structures. Part I.

20. IS 2062:2006 Indian Standard Hot Rolled Low, Medium and High Tensile Structural Steel.

21. MBMA (2006) Low Rise Building Systems Manual, Metal Building Manufactures Association, Cleveland, Ohio.

22. Ramesh Meghrajani, "Behaviour of Web-Tapered Built-Up Sections as Beam-Column Members in PreEngineered Steel Buildings", thesis VNIT 2016.

23. R.M. Peixoto, M.S. Seif, L.C.M. Vieira Jr., "Double-shear tests of high-strength structural bolts at elevated temperatures", Fire Safety Journal, Vol. 94, pp. 8-12, 2017. 
24. Shubham Mishra, S. P. Siddh, R. V. Meghrajani, "Ready Reckoner for Load Capacity of Moment Connection in Pre-engineered Steel Buildings", Journal of Advanced Research in Dynamical and Control Systems Volume 11, 06-Special Issue, pp. 237-242, 2019.

25. Thomas M. Murray, "Recent Developments for the Design of Moment End-Plate Connections", Journal of Construction Steel Research, pp. 133-162, October 1988, Elsevier Science Publishers Ltd.

26. Zamil Steel Design manual.

27. Zhongwei Zhao, Bing Liang, Haiqing Liu, Yongjing Li, "Simplified numerical model for high-strength bolted connections”, Engineering Structures, Volume 164, 1 June 2018, Pages 119-127. 